\title{
Loss of resting bradycardia with detraining is associated with intrinsic heart rate changes
}

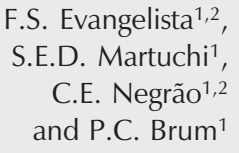

\author{
${ }^{1}$ Departamento de Biodinâmica do Movimento do Corpo Humano, \\ Escola de Educação Física e Esporte, ' Instituto do Coração, \\ Faculdade de Medicina, Universidade de São Paulo, São Paulo, SP, Brasil
}

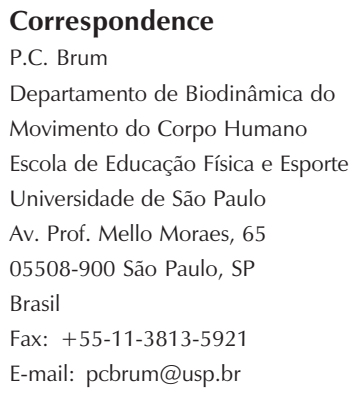

Received September 29, 2004 Accepted April 18, 2005

\begin{abstract}
The mechanisms underlying the loss of resting bradycardia with detraining were studied in rats. The relative contribution of autonomic and non-autonomic mechanisms was studied in 26 male Wistar rats (180-220 g) randomly assigned to four groups: sedentary ( $\mathrm{S}, \mathrm{N}=6$ ), trained ( $\mathrm{T}, \mathrm{N}=8)$, detrained for 1 week $(\mathrm{D} 1, \mathrm{~N}=6)$, and detrained for 2 weeks (D2, N = 6). T, D1 and D2 were treadmill trained 5 days/week for 60 min with a gradual increase towards $50 \%$ peak $\mathrm{VO}_{2}$. After the last training session, D1 and D2 were detrained for 1 and 2 weeks, respectively. The effect of the autonomic nervous system in causing training-induced resting bradycardia and in restoring heart rate (HR) to pre-exercise training level (PET) with detraining was examined indirectly after cardiac muscarinic and adrenergic receptor blockade. $\mathrm{T}$ rats significantly increased peak $\mathrm{VO}_{2}$ by 15 or $23.5 \%$ when compared to PET and $\mathrm{S}$ rats, respectively. Detraining reduced peak $\mathrm{VO}_{2}$ in both D1 and D2 rats by $22 \%$ compared to $\mathrm{T}$ rats, indicating loss of aerobic capacity. Resting HR was significantly lower in T and D1 rats than in $\mathrm{S}$ rats $(313 \pm 6.67$ and $321 \pm 6.01$ vs $342 \pm 12.2 \mathrm{bpm})$ and was associated with a significantly decreased intrinsic HR (368 \pm 6.1 and $362 \pm 7.3$ vs $390 \pm 8 \mathrm{bpm}$ ). Two weeks of detraining reversed the resting HR near PET $(335 \pm 6.01 \mathrm{bpm})$ due to an increased intrinsic HR in D2 rats compared with T and D1 rats (376 $\pm 8.8 \mathrm{bpm})$. The present study provides the first evidence of intrinsic HR-mediated loss of resting bradycardia with detraining in rats.
\end{abstract}

Endurance exercise training is generally defined as any regularly performed aerobic activity involving the use of large muscle groups for a sufficient duration and intensity to train the cardiorespiratory systems. In previously sedentary subjects, aerobic exercise training increases maximal exercise performance, as reflected by an increase in peak oxygen uptake (peak $\mathrm{VO}_{2}$ ) (1). In addition,
Key words

- Exercise training

- Cardiac autonomic balance

- Heart rate

- Peak oxygen uptake

- Detraining aerobic exercise training leads to an improvement of cardiovascular capacity, which is associated with lower resting and submaximal heart rates (HR) and increased ventricular weight and volume. These cardiovascular adaptations induced by aerobic exercise training are of clinical relevance since both are associated with increased life expectancy and decreased cardiovascular events (2). 
Even though increased peak $\mathrm{VO}_{2}$ and resting bradycardia are related to better exercise performance and cardiovascular functioning, these responses are gradually lost when the training is discontinued. A significant decline in cardiovascular function and muscle metabolic potential occurs with days or weeks of detraining and is associated with a significant reduction in peak $\mathrm{VO}_{2}$ (3).

The mechanisms involved in the improvement of exercise performance and cardiovascular functioning by aerobic exercise training have been extensively studied $(1,4)$. Conversely, little is known about the physiological mechanisms responsible for detraining. Recently, Kemi et al. (5) observed a close association between decreased peak $\mathrm{VO}_{2}$ and cardiac myocyte length changes after 4 weeks of detraining in rats. Regarding the resting HR, the mechanisms underlying the loss of resting bradycardia with detraining have not been defined.

Thus, the aims of the present investigation were to study in male Wistar rats: 1) the time needed for HR to be reversed to the preexercise training level, 2) the relative contribution of the vagal and sympathetic control of resting HR after detraining, and 3) the intrinsic heart rate (IHR) after detraining. We hypothesized that a complete reversal of resting HR to pre-exercise training levels would take place within 2 weeks of detraining and would be associated with an increased IHR.

Twenty-six male Wistar rats (180-220 g) were randomly assigned to four groups: sedentary $(S, N=6)$, trained $(T, N=8)$, detrained for 1 week $(\mathrm{D} 1, \mathrm{~N}=6)$, and detrained for 2 weeks (D2, N =6). Rats were housed 35 per cage in a temperature-controlled room $\left(22^{\circ} \mathrm{C}\right)$ with a $12: 12$-h dark-light cycle, with free access to standard laboratory chow (Nuvital Nutrientes S/A, Curitiba, PR, Brazil) and tap water. The study was conducted according to the ethical principles in animal research adopted by the Brazilian College of Animal Experimentation (www.cobea.org.br).
Exercise training was started when the rats were 8 weeks old and consisted of 10 weeks of running on a motor treadmill (ESD model 01, FUNBEC, São Paulo, SP, Brazil) 5 days a week for $60 \mathrm{~min}$ at $50 \%$ of peak $\mathrm{VO}_{2}$, as described elsewhere (6). The training sessions were held during the rat's dark cycle, which in the present study was from 7:00 am to 7:00 pm. The sedentary rats were handled every day for habituation to the experimental protocols. Peak $\mathrm{VO}_{2}$ was measured by expired gas analysis during increasing exercise on a motor treadmill from 5 to $40 \mathrm{~m} / \mathrm{min}$ in $5 \mathrm{~m} / \mathrm{min}$ increments every $3 \mathrm{~min}$ and no grade until exhaustion (6). Rats were considered to be exhausted when they could no longer run at the treadmill speed. Oxygen and carbon dioxide concentrations were determined by the Scholander microtechnique using a Godart-Statham spirometer (Bilthoven, Netherlands). Peak $\mathrm{VO}_{2}$ was determined at the maximum speed reached during the progressive exercise testing. The treadmill exercise test was repeated after 5 weeks of exercise training in order to adjust training intensity and at the end of the experimental protocol. After the last training session, the D1 and D2 groups were submitted to detraining for 1 and 2 weeks, respectively, when physical activity was restricted to the space of their cage.

One day after the last training session or detraining period, resting HR and HR after autonomic blockade were evaluated. For this procedure, 3 stainless steel electrodes $(5 \mathrm{~cm}$ long and $0.55 \mathrm{~mm}$ in diameter) were implanted subcutaneously under ketamine (50 $\mathrm{mg} / \mathrm{kg}$, ip $)$ and xylazine $(10 \mathrm{mg} / \mathrm{kg}$, ip $)$ anesthesia, and attached to the right and left axillary areas and dorsum (7). The electrodes were used to monitor the electrocardiography (EKG) results with a multichannel recorder (model 7754A, HewlettPackard, Palo Alto, CA, USA) as measures of HR. Simultaneously, the EKG signal was fed to a 16-channel analog-to-digital converter and then to a microcomputer using an 
AT/CODAS system at $500 \mathrm{~Hz}$ (DataQ Instruments Inc., Akron, OH, USA).

Vagal and sympathetic tone was studied during the rat's dark cycle by intravenous injections of $3 \mathrm{mg} / \mathrm{kg}$ methylatropine and 4 $\mathrm{mg} / \mathrm{kg}$ propranolol (Sigma Aldrich Corporation, São Paulo, SP, Brazil), 24 h after the electrode implantation (7). On the first day of the study, resting HR was recorded in quiet unrestrained animals kept in their individual cages and methylatropine was injected immediately after the recording. Because the HR response to methylatropine reaches its peak within $10-15 \mathrm{~min}$, this time interval was standardized before the HR measurement. Propranolol was injected 15 min after methylatropine injection, and HR was measured again after 10-15 min.

The IHR was evaluated after simultaneous blockade with propranolol and methylatropine. We have observed that these drugs were promoting blockade $30 \mathrm{~min}$ after injection. On the 2nd day of the study, propranolol was administered first to obtain the inverse sequence of blockade (7).

The vagal effect was evaluated as the difference between the maximum HR after methylatropine injection and the control HR. The sympathetic effect was evaluated as the difference between the control HR and minimum HR after propranolol injection. The terminology regarding the vagal and sympathetic effect has been described by some of us (7), as well as the procedure used to estimate the vagal and sympathetic contribution to the maintenance of control HR.

Vagal tone was calculated as the difference between IHR and HR after propranolol injection. The sympathetic tone was determined as the difference between the HR after methylatropine injection and the IHR. The vagal and sympathetic tone estimate the maximal tachycardic and bradycardic response to methylatropine and propranolol, respectively (7).

Data are reported as means $\pm \mathrm{SD}$. Comparisons among groups were made using appropriate ANOVA followed by the post hoc Bonferroni $t$-test, with the level of significance set at $\mathrm{P} \leq 0.05$.

Peak $\mathrm{VO}_{2}$ has been associated with an improvement in functional cardiovascular capacity, and its decline is frequently used to measure the detraining effect (3). Ten weeks of exercise training increased peak $\mathrm{VO}_{2}$ in $\mathrm{T}$ rats compared to the pre-exercise period (15\%) and compared to $\mathrm{S}$ rats $(23.5 \%$; Table 1). After exercise training, peak $\mathrm{VO}_{2}$ declined by $22 \%$ in both D1 and D2 rats compared to $\mathrm{T}$ rats. Moreover, no significant difference was observed in peak $\mathrm{VO}_{2}$ in $\mathrm{D} 1$ and D2 rats compared to the pre-exercise period. Thus, the reduction of peak $\mathrm{VO}_{2}$ indicates a loss in aerobic capacity during the detraining period.

Resting bradycardia is considered to be a physiological marker for aerobic adaptation to exercise training, and the time course of resting bradycardia loss coincides with a reduction in both submaximal and maximal exercise performance (8). Figure 1 shows the time course of resting HR during the training and detraining periods. The resting HR of trained and 1-week detrained rats was significantly lower than that of their sedentary litter mates $(313 \pm 6.67$ and $321 \pm 6.01$ vs $342 \pm 12.2 \mathrm{bpm}$ for trained, 1-week de-

\begin{tabular}{|c|c|c|}
\hline & \multicolumn{2}{|c|}{ Peak VO $2\left(\mathrm{ml} \mathrm{kg}^{-1} \mathrm{~min}^{-1}\right)$} \\
\hline & Before & After \\
\hline$S$ & $71 \pm 2.2$ & $68 \pm 4.8$ \\
\hline $\mathrm{T}$ & $73 \pm 3.2$ & $84 \pm 1.6^{*}$ \\
\hline D1 & $68 \pm 2.9$ & $74 \pm 1.3$ \\
\hline D2 & $75 \pm 6.8$ & $74 \pm 1.6$ \\
\hline
\end{tabular}

Data are reported as mean \pm SEM. As shown, peak $\mathrm{VO}_{2}$ was significantly increased in $\mathrm{T}$ rats. However, detraining rapidly reduced peak $\mathrm{VO}_{2}$, which leveled off by the first week of detraining. ${ }^{*} \mathrm{P} \leq 0.05$ vs $\mathrm{S}$ rats (two-way ANOVA). 
trained and sedentary rats, respectively). In contrast, the HR values of 2-week detrained rats were similar to those of the sedentary rats $(335 \pm 6.01$ vs $342 \pm 12.2$ bpm, respectively). These results indicate that 2 weeks of detraining reversed the resting HR response to exercise training, with values returning to near pre-exercise training levels.

To study the mechanisms underlying the loss of resting bradycardia with detraining, the IHR and sympathetic and parasympathetic cardiac autonomic control were calculated. No difference was observed in cardiac vagal or sympathetic tone among the groups studied (Figure 1). Likewise, no difference was observed among the groups studied in either vagal $(S, 144 \pm 14.7$; $T, 115 \pm 9.3$; D1, $136 \pm 14.4$, and D2, $108 \pm 21.8 \mathrm{bpm}$ ) or sympathetic $(\mathrm{S}, 28 \pm 8.3 ; \mathrm{T}, 16 \pm 4.7$; D1, 21 \pm 6.4 , and D2, $15 \pm 6.2 \mathrm{bpm}$ ) effects. Therefore, the main mechanism accounting for the return of resting $\mathrm{HR}$ to near pre-exercise training levels in $\mathrm{D} 2$ rats was associated with changes in IHR. In fact, the IHR of T rats was significantly lower than that of their $\mathrm{S}$ litter mates $(368 \pm 6.1$ vs $390 \pm 8$ bpm, $\mathrm{P} \leq$

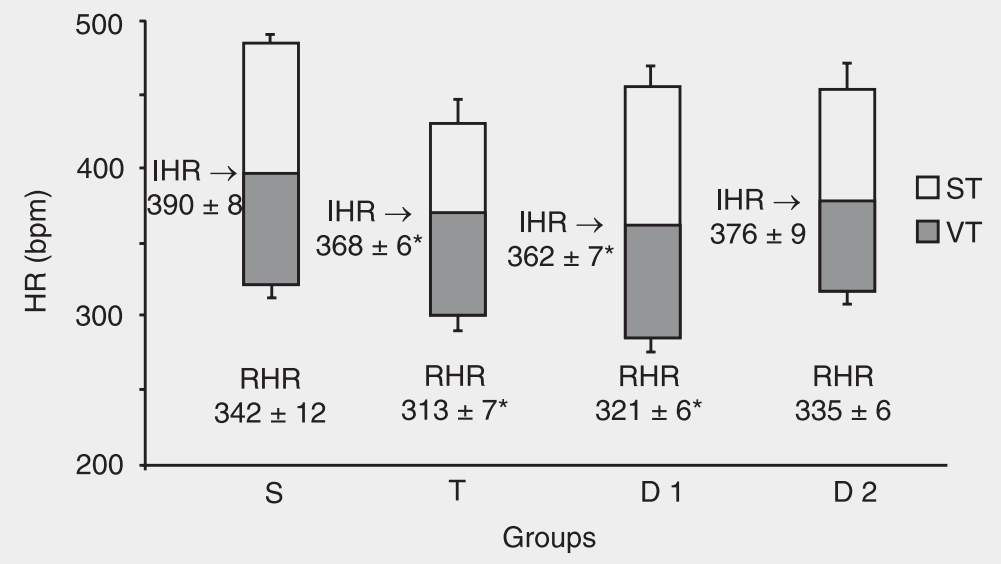

Figure 1. Vagal (VT) and sympathetic (ST) tone and resting heart rate (RHR) in sedentary (S) and trained (T) rats, and in rats detrained for 1 week (D1) and for 2 weeks (D2; see Material and Methods for calculation). IHR = intrinsic heart rate. Data are reported as means \pm SEM. ${ }^{*} \mathrm{P} \leq 0.05$ vs $\mathrm{S}$ rats (one-way ANOVA). Note that exercise training induced resting bradycardia, which was paralleled by a reduction in IHR. Of interest, the partial reversal of RHR to pre-exercise training levels was associated with an increased IHR.
0.05). One week of detraining kept the IHR at lower levels when compared to sedentary rats $(362 \pm 7.3$ vs $390 \pm 8$ bpm, $\mathrm{P} \leq 0.05)$. However, the IHR of D2 rats was partially reversed by $96 \%$, suggesting a partial recovery of IHR in this group when compared to sedentary litter mates $(376 \pm 8.8$ vs $390 \pm 8$ bpm).

Cardiovascular and metabolic adaptations to regular exercise training are highly dynamic. Upon detraining, most of the exercise-gained aerobic fitness acquired over 23 months is lost within a few weeks $(5,9)$. In the present investigation, we observed an almost complete regression of resting HR in rats by the second week of detraining. In addition, we observed an even more rapid time course for the decline in peak $\mathrm{VO}_{2}$, which leveled off by the first week of detraining.

Detraining is characterized by a rapid decline in peak $\mathrm{VO}_{2}(9)$, and both the magnitude and time course of its decay are influenced by several factors, including the species studied. In the present study, we observed a fall of $11.9 \%$ in peak $\mathrm{VO}_{2}$ already by the first week of detraining, when peak $\mathrm{VO}_{2}$ leveled off at the sedentary rat level.

Of interest, peak $\mathrm{VO}_{2}$ decline has been indicated as a good marker for the cardiovascular consequences of detraining (3), since it parallels decreases in peak cardiac output and stroke volume. Further declines are related to decreases in arteriovenous difference. Presently, decreased peak $\mathrm{VO}_{2}$ was followed by an increase in resting HR, which was completely reversed to the sedentary and/or pre-exercise training levels by the second week of detraining.

Resting bradycardia has been considered to be the hallmark of exercise training adaptation in both animals $(10,11)$ and humans (12). Moreover, training-induced bradycardia seems to be associated with lower myocardium oxygen uptake and increased stroke volume (13). The mechanisms underlying the resting bradycardia have been exten- 
sively studied, and increased cardiac vagal activity $(10,14)$, decreased cardiac sympathetic activity $(10)$ and lower IHR $(7,12,15)$ have been reported.

The present findings demonstrate a reduced IHR associated with lower resting HR in exercise-trained rats. These data corroborate our previous findings of decreased IHRmediated bradycardia in running-exercised rats (7). However, the influence of training mode on cardiac autonomic balance deserves special attention, since we recently observed a vagally mediated resting bradycardia in swimming-trained rats (16). In humans, the mechanisms underlying resting bradycardia remain debatable. Some investigators have reported increased cardiac vagal activity (17) as determined by spectral analysis of HR variability. In contrast, others have observed a decreased IHR $(14,15)$ or reduced atrioventricular conduction (18) in spite of no changes in cardiac sympathovagal balance. These contrasting results may be related, at least in part, to the methodological approach used to isolate the vagally mediated influence of respiration. Some investigators have recently observed no changes in HR variability and respiratory sinus arrhythmia under spontaneous or imposed breathing conditions in athletes compared with age-matched non-athletes, adding support to a contribution of a decrease in IHR to explain traininginduced bradycardia in athletes (15).

Another striking finding of our study was the reversibility of resting HR with detraining and its association with changes in IHR. Two weeks of detraining increased the rest- ing HR by $7 \%$, an event that was temporally paralleled by a $2 \%$ increase in IHR. Since changes in IHR are involved in resting bradycardia, it is not surprising that IHR would be associated with the effects of detraining on resting HR. Therefore, the present study suggests that resting HR reversibility with detraining is at least in part IHR-mediated. Whether similar adaptations take place in humans is under investigation. In professional football players (19), in spite of the high intensity of the training period, no significant changes in cardiac autonomic balance were observed between training and detraining conditions, probably due to the short duration of the detraining period (30 days). Yet, Crandall et al. (20) observed a reduced cardiac vagal activity in healthy men following 15 days of head-down bed rest. It is worth mentioning that even though bed rest studies are often used to model the cardiovascular detraining associated with space flight, athletes are not usually completely immobile during periods of detraining. As a result, generalization from studies employing bed rest to elicit detraining may not be directly applicable to athletes.

This study is the first to provide evidence for IHR-mediated loss of resting bradycardia with detraining in rats. These alterations, if reproducible in humans, will add new knowledge about the loss of cardiovascular benefits such as resting bradycardia in humans, since many factors, such as the offseason, injury, and travel may periodically limit training.

\section{References}

1. Bassett Jr DR \& Howley ET (2000). Limiting factors for maximum oxygen uptake and determinants of endurance performance. Medicine and Science in Sports and Exercise, 32: 70-84.

2. Morris CK \& Froelicher VF (1993). Cardiovascular benefits of improved exercise capacity. Sports Medicine, 16: 225-236.

3. Convertino VA, Polet JL, Engelke KA, Hoffler GW, Lane LD \& Blomqvist CG (1995). Increased beta-adrenergic responsiveness induced by 14 days exposure to simulated microgravity. Journal of
Gravitational Physiology, 2: P66-P67.

4. Carter JB, Banister EW \& Blaber AP (2003). Effect of endurance exercise on autonomic control of heart rate. Sports Medicine, 33: 33-46.

5. Kemi OJ, Haram PM, Wisloff U \& Ellingsen O (2004). Aerobic fitness is associated with cardiomyocyte contractile capacity and endothelial function in exercise training and detraining. Circulation, 109: 2897-2904. 
6. Veras-Silva AS, Mattos KC, Gava NS, Brum PC, Negrao CE \& Krieger EM (1997). Low-intensity exercise training decreases cardiac output and hypertension in spontaneously hypertensive rats. American Journal of Physiology, 273: H2627-H2631.

7. Negrao CE, Moreira ED, Brum PC, Denadai ML \& Krieger EM (1992). Vagal and sympathetic control of heart rate during exercise by sedentary and exercise-trained rats. Brazilian Journal of Medical and Biological Research, 25: 1045-1052.

8. Houmard JA, Hortobagyi T, Johns RA, Bruno NJ, Nute CC, Shinebarger MH \& Welborn JW (1992). Effect of short-term training cessation on performance measures in distance runners. International Journal of Sports Medicine, 13: 572-576.

9. Mujika I \& Padilla S (2001). Cardiorespiratory and metabolic characteristics of detraining in humans. Medicine and Science in Sports and Exercise, 33: 413-421.

10. De Angelis K, Wichi RB, Jesus WR, Moreira ED, Morris M, Krieger EM \& Irigoyen MC (2004). Exercise training changes autonomic cardiovascular balance in mice. Journal of Applied Physiology, 96: 2174-2178.

11. Evangelista FS, Brum PC \& Krieger JE (2003). Duration-controlled swimming exercise training induces cardiac hypertrophy in mice. Brazilian Journal of Medical and Biological Research, 36: 17511759.

12. Katona PG, McLean M, Dighton DH \& Guz A (1982). Sympathetic and parasympathetic cardiac control in athletes and nonathletes at rest. Journal of Applied Physiology, 52: 1652-1657.

13. Wisloff U, Loennechen JP, Falck G, Beisvag V, Currie S, Smith G \& Ellingsen $O$ (2001). Increased contractility and calcium sensitivity in cardiac myocytes isolated from endurance trained rats. Cardiovascular Research, 50: 495-508.
14. Catai AM, Chacon-Mikahil MP, Martinelli FS et al. (2002). Effects of aerobic exercise training on heart rate variability during wakefulness and sleep and cardiorespiratory responses of young and middleaged healthy men. Brazilian Journal of Medical and Biological Research, 35: 741-752.

15. Scott AS, Eberhard A, Ofir D, Benchetrit G, Dinh TP, Calabrese P, Lesiuk V \& Perrault H (2004). Enhanced cardiac vagal efferent activity does not explain training-induced bradycardia. Autonomic Neuroscience, 112: 60-68.

16. Medeiros AM, Oliveira EM, Gianolla R, Casarini DE, Negrão CE \& Brum PC (2004). Swimming training increases cardiac vagal effect in rats. Brazilian Journal of Medical and Biological Research, 37: 1909-1917.

17. Yamamoto K, Miyachi M, Saitoh T, Yoshioka A \& Onodera S (2001). Effects of endurance training on resting and post-exercise cardiac autonomic control. Medicine and Science in Sports and Exercise, 33: 1496-1502.

18. Stein R, Medeiros CM, Rosito GA, Zimerman LI \& Ribeiro JP (2002). Intrinsic sinus and atrioventricular node electrophysiologic adaptations in endurance athletes. Journal of the American College of Cardiology, 39: 1033-1038.

19. Rebelo AN, Costa O, Rocha AP, Soares JM \& Lago P (1997). Is autonomic control of the heart rate at rest altered by detraining? A study of heart rate variability in professional soccer players after the pretraining period and after the preparatory period for competitions. Revista Portuguesa de Cardiologia, 16: 535-541.

20. Crandall CG, Engelke KA, Pawelczyk JA, Raven PB \& Convertino VA (1994). Power spectral and time based analysis of heart rate variability following 15 days head-down bed rest. Aviation, Space and Environmental Medicine, 65: 1105-1109. 